\title{
TCOM \\ Science stories as culture: experience, identity, narrative and emotion in public communication of science
}

\author{
Sarah R. Davies, Megan Halpern, Maja Horst, David A. Kirby and \\ Bruce Lewenstein
}

\begin{abstract}
The last three decades have seen extensive reflection concerning how science communication should be modelled and understood. In this essay we propose the value of a cultural approach to science communication - one that frames it primarily as a process of meaning-making. We outline the conceptual basis for this view of culture, drawing on cultural theory to suggest that it is valuable to see science communication as one aspect of (popular) culture, as storytelling or narrative, as ritual, and as collective meaning-making. We then explore four possible ways that a cultural approach might proceed: by mobilising ideas about experience; by framing science communication through identity work; by focusing on fiction; and by paying attention to emotion. We therefore present a view of science communication as always entangled within, and itself shaping, cultural stories and meanings. We close by suggesting that one benefit of this approach is to move beyond debates concerning 'deficit or dialogue' as the key frame for public communication of science.
\end{abstract}

Keywords

DOI

Introduction
Science and technology, art and literature; Science communication: theory and models

https://doi.org/10.22323/2.18050201

Submitted: 28th February 2019

Accepted: 10th June 2019

Published: 14th October 2019

We live in societies that are increasingly marked by their reliance on science and technology, and as such it is widely agreed that public communication around such science and technology is essential to the functioning of contemporary democracies [Felt and Wynne, 2007; Jasanoff, 2017]. There has therefore been extensive reflection, over at least the last three decades, concerning how we - scholars and practitioners of science communication - should think about and conceptualise public science communication. How should we model it [Brossard and Lewenstein, 2010; Longnecker, 2016; Trench, 2008]? What is the best way to teach it [Bray, France and Gilbert, 2012; Silva and Bultitude, 2009; Baram-Tsabari and Lewenstein, 
2017]? What are the most effective means of communication [Broks, 2017; Bucchi, 2013; Illingworth and Allen, 2016]? These efforts are by nature challenging given that there is widespread agreement that the communication landscape is one that is rightly diverse [Bucchi, 2008; Davies and Horst, 2016]. Science communication formats range from popular science books to participatory citizens juries, social media campaigns to science cafes. Capturing what is happening in all of these, or finding a way to think about them collectively, has involved reflection on the nature of communication, of science, and of public audiences themselves [Bucchi and Trench, 2014; Michael, 2002].

In this essay we wish to contribute to these debates by highlighting one approach that we find productive: understanding science communication through the frame of culture. This view - as we will demonstrate - takes us away from considerations of information transfer or effectiveness, and instead leads us to consider science communication as something experiential and emotional - as something that is concerned with the creation of shared meanings, and that is therefore deeply connected to the nature and ideologies of contemporary societies. Such an approach is not new but is, we think, timely, relating as it does to the increasingly prevalent sense that science communication is not external to (popular) culture and wider consumption of entertainment media, but is an important part of it [Kaiser et al., 2014]. A cultural approach to science communication thus acknowledges that public stories about science (as we understand science communication) should not be construed as fundamentally different to other kinds of public storytelling, but as both intertwined with, and bearing marked similarities to, public culture and entertainment [Fahy and Caulfield, 2016; Fahy and Lewenstein, 2014]. It also offers a frame for thinking about the nature of science communication that is somewhat different to existing models, by representing it, in all its diverse forms, as meaning-making. Our central argument is that, by drawing on well-established aspects of cultural theory - experience, narrative, identity, and affect, for example - to unpack processes of meaning-making, we can find important tools for imagining and analysing public communication and the stories told within it.

In what follows we first briefly outline what it means to understand science communication as culture before demonstrating, in four sections, what a cultural approach can offer to those who think about, analyse, and carry out public communication of science.

Science communication as culture
What does it mean to view science communication as culture? Given the contested nature of theories of 'culture' [Hall, 1997], any such view requires a multi-faceted approach that acknowledges that culture can be understood in different ways. A first line of thought, for instance, frames science and science communication as aspects of (popular) culture. Here culture is used in its sense of "a state of intellectual refinement associated with the arts, philosophy and learning" [du Gay et al., 1997, p. 11]. 'Culture' is therefore the way a society expresses itself, and the (multiple) ways that it articulates the human condition - whether that is expressed through the paintings of Mark Rothko, the image of the double helix, or the TV show The Wire. When Durant, Evans and Thomas [1989] claim that "science is arguably the greatest achievement of our culture, and people deserve to know about it" (p. 11), they are calling upon this idea of societal expression, contrasting it 
with more instrumental visions of science as useful for personal or civic goals. To take science as culture in this way is to understand it not only as relating to the scientific, technical, political, or economic aspects of a society, but to its artistic and social expressions. Science is an achievement of our societies, and its representation within public communication should be understood as being as much about contemporary popular culture as contemporary science. This view of culture therefore encourages us to look at science communication in the same way that we study other cultural forms, from TV to music, and to explore the ways in which science's stories are told across our societies.

A second, perhaps more profound, view of culture frames it as collective meaning-making. The anthropologist Clifford Geertz rather beautifully writes that:

Believing, with Max Weber, that man [sic] is an animal suspended in webs of significance he himself has spun, I take culture to be those webs, and the analysis of it to be therefore not an experimental science in search of law but an interpretive one in search of meaning. [Geertz, 1973, (1993), p. 5]

If culture comprises the 'web' through which each of us makes sense of the world, seeing science communication as culture encourages us to understand it as a space of collective meaning-making. It is not simply an aspect of the 'intellectual refinement' of societies (to re-quote du Gay et al. from above), but the mundane "production and the exchange of meanings - the 'giving and taking of meaning' - between the members of a society or group" [Hall, 1997, p. 2]. This is significant in part because it flies against commonsense assumptions that science communication is primarily concerned with the transmission or negotiation of information [Davies and Horst, 2016; Michael, 2002]. In this view, rather than public communication being about the transfer of certain facts - the nature of DNA, the scientific method, whether vaccines cause autism - it is instead about how particular societies or groups explain the world. Understanding science communication as meaning-making therefore draws our attention to its functions at the level of shared identities and imaginations, alongside its undoubted role in disseminating particular scientific notions.

This shift in analytical emphasis from transmission to culture echoes similar discussions in communication research. In his essays on communication as culture, James Carey [1989] offers a ritual view of communication as an alternative to a transmission model. The ritual view, he says, "is directed not toward the extension of messages in space but toward the maintenance of society in time; not the act of imparting information but the representation of shared beliefs" (p. 5). He uses the (perhaps outdated) example of reading a newspaper to explore this ritual view. People may have learned something while reading newspapers, but they did not read to comprehend information. Rather, the newspaper was part of a shared experience; a ritual that, like a Catholic mass, allowed people to perform and confirm a particular worldview.

As the comparison with religious ritual suggests, meaning-making is often, in practice, storytelling: from the earliest myths to contemporary story-based podcasts [Kaiser et al., 2014; Linett, 2013], human animals have used narrative to explain the world around them. There there have been various efforts to explore a 
culture-based understanding of science and science communication in terms that reference story and narrative. For Jasanoff and Kim [2015], for instance, public presentations of science convey 'sociotechnical imaginaries': "collectively held, institutionally stablilized, and publicly performed visions of desirable futures" (p. 4) that imply sets of assumptions about social and political orders. Similarly, Felt and Wynne [2007] have described the 'master narratives' that govern European science policy and public debate. Conceptual tools such as these point us to ways in which understanding science communication in cultural terms can aid us as both analysts and practitioners. In particular, they bring us to the idea that studying and carrying out public communication might be most productive in focusing on the meanings that are created through particular public stories about science. Such an approach encourages us to ask not whether facts are being successfully transmitted, but what is being made or reinforced through particular instances of public storytelling about science: this might be, for instance, ideas about the nature of science, assumptions about wider society, or new collectives or identities [Davies and Horst, 2016; Halpern, 2012; Horst and Michael, 2011].

In making this our central claim it is important to acknowledge that thinking about culture, and science communication as culture, goes far beyond the lines of enquiry we have outlined. Most recently, for instance, Gwendolyn Blue [2018] has further developed arguments concerning the ritualistic aspects of science communication as being central to a culture-based approach. For others, science communication is increasingly framed as just one kind of 'cultural event' amongst many [Sardo and Grand, 2016]. But for our purposes this brief outline serves as an introduction to our claim that understanding science communication as culture can offer new insights into its practice and analysis. The rest of this essay seeks to demonstrate this by picking up on four ways that such an approach might frame and study science communication. Culture, as we have said, is contested and multivalent; to use it as a basis for understanding science communication therefore offers multiple ways in to it. In what follows we focus on four of these access points: experience; identities; fiction; and emotion. These frames are not exhaustive, but demonstrate four starting points for analysis that readers may wish to mobilise or further develop. In discussing each of these we outline what it means to think science communication through them, while pointing to the ways in which they are intertwined with culture, meaning-making, and storytelling.

\subsection{Science communication as experience}

One way in to culture is through notions of experience. Dewey's theories of experience [1934; 1938] offer a lens through which to view not only one-off experiences associated with science communication interventions, but also the wider lived experiences within which these moments occur. If we continue Geertz' metaphor of webs of significance, experiences might be the moments of meaning around which we spin our webs. Experience, according to Dewey, involves an interaction with an expressive object and with the continuum of experience that comprises our lives. Any intervention in science communication is thus interpreted through the lifelong cumulation of ubiquitous representations of science, both mundane and meaningful. Life-saving medical treatments, science fiction films, commercials for cleaning products, and medication labels all play a role in shaping people's lives and their relationships to science. A cultural approach to science 
communication is therefore concerned with how meanings are constructed both within individual experiences and wider experience continuums.

Practically, this framing of communication as experience asks researchers and practitioners to shift their focus from knowledge, behaviour, and attitudes to interpretation, meaning, and significance, without placing undue importance or weight on any particular intervention. For Dewey, experiences were interactions with the objects or events in the world, but these interactions do not happen without context. Rather, they are part of a continuum of experience. "The two principles of continuity and interaction are not separate from each other. They intercept and unite. They are, so to speak, the longitudinal and lateral aspects of experience" [1938, p.44]. Interactions themselves are also composed of what Dewey calls the objective conditions of the experience (the event, text, artwork, or other object of the experience) and the interpretations an individual brings to it.

Experiences do not happen within either the object or the mind. Instead, they lie at the meeting point between the two.

Aesthetic experiences have a narrative form and are therefore contained: they have a beginning, middle, and end. Dewey suggests that a meal, an argument, or a moment in nature might spark an aesthetic experience. In terms of science, one might have such an experience at a doctor's visit, a museum exhibition, or a popular movie. An experience has meaning and significance, but it need not be meaningful or deeply significant. Experiences culminate and conclude. Their valence can be positive or negative, or anything in between, and they can evoke a desire for further experiences - or the opposite. Experiences are personal and unique to each of us; however, the objects we have experiences with are often shared, and, often, similar lived experiences will provoke similar experiences. For example, many girls and young women have had experiences with science which led them to see science as something that was outside the scope of their abilities or interests. In the US or Europe, for instance, the majority of cumulative experiences with scientists might well be with them being represented by, or being, white males. The accumulation of such experiences inevitably suggests something about what it means to be a scientist. Experiences which feature women in science may, then, hold particular significance, whether they are fleeting stories about women who have won awards, or wider cultural phenomena such as the book and film Hidden Figures. This story, in its different forms, not only provided new meanings for what it meant to be a scientist (black, young, a woman), but also, perhaps, a new set of meanings around the history of science, the space race, and the cold war.

Just as experiences inform and shape lived experience, however, the countless moments we do not attend to also add up. Though there are many messages with which we do not engage, or abandon out of distraction or lack of interest, these messages accumulate along with our experiences and contribute to shaping our lived experience. Such mundane moments add up, and they contribute to the ways we make meaning from experiences. Most people don't formally study science past secondary education, so for most of their lives, interactions with science come from informal encounters at home, in the media, or in public spaces [National Research Council, 2009]. Though some seek out these encounters at museums and other informal venues, all of us encounter science in our daily lives in small, mundane ways. So even though we rarely attend to, for example, advertisements for cold medicine or household cleaners, our cumulative interactions with germ theory may 
well come from repeated exposure to commercials and print advertisements that make claims about germs as part of their sales pitch.

Medical knowledge is a good example of this. In the United States, pharmaceutical companies can market prescription medications directly to members of the public, through the same media and in the same format as advertisements for cleaning products, food, and entertainment. This shapes relationships people have with medications: they are products we can choose to suit our needs and desires. Commercials for erectile dysfunction medications appear alongside commercials for fast food restaurants, cleaning products, and electronic devices. Though we may not attend to these commercials - especially if these kinds of medication don't pertain to us - we do understand them as consumer products, from which we can pick and choose. The significance of this relationship becomes salient when we are asked by medical professionals to use products from these same companies in the form of vaccinations. Again, we address the suggestion as a consumer choice, not as a medical or scientific prescription.

Viewing science as experience thus provides new directions for both researchers and practitioners wishing to communicate. By examining the meanings made through specific experiences and continuums of experience, researchers uncover new questions and methods for exploring the situatedness of public perceptions of science. For science communicators, the lens of experience shifts the focus of their work from explanation to expression, and from the transmission of scientific knowledge to the making of meanings around scientific concepts. While the former might draw on narrative, affect, or emotion as tactics for transmission, the latter takes these as central aspects of any interaction.

\subsection{Science communication as identity work}

Understanding science communication as story-telling about science also points to its importance for identity work of both individuals and collectives. In organisation studies, story-telling has been seen as a crucial part of creating internal coherence and alignment around a shared sense of who 'we' are and what the shared purpose of the organization is and should be [Czarniawska, 1997] — building, in other words, a strong organisational culture [Kunda, 2006]. Karl Weick goes so far as to argue that the organisation only knows who its 'we' is, when members look at its actions and retrospectively try to make sense of them [Weick, 2000]. It is by telling stories about our own actions and giving them meaning that we construct our own identities. Such work is therefore also a constant emergence - an identity is never a finalised entity, but is always under construction [Taylor and van Every, 2008]. A similar argument can be found in narrative psychology about the identity of individuals [Sarbin, 1986]. A cultural approach to science communication is therefore concerned with how identities - whether of individuals or institutions - are negotiated in public storytelling about science.

Organisational communication scholars distinguish between identity, image and reputation of the organisation [Hatch and Schultz, 1997]. While 'identity' is the internal construction closest related to the organisational culture, 'image' designates the way the organisation represents itself to the outside world and 'reputation' covers the identity as perceived by external actors. These aspects are of 
course related, and are not only influenced by deliberate communication actions. When scientists communicate in public they are constructing imaginations of their own identity as well as that of their scientific organization and the institution of science [Horst, 2013]. Seeing science communication as public story-telling about science therefore influences both the internal identity construction and external images of science.

Modern scientific organisations conduct large amounts of public relations in order to achieve a good reputation, which can be exchanged into the generation of resources and legitimacy [Bauer and Gregory, 2007; DiMaggio and Powell, 1983]. One aspect is the recruitment of young talents to choose careers in STEM subjects. For that purpose organisations frequently produce stories and commercials that are designed to portray a scientific career as glamorous, exciting and important. These success stories, however, rarely leave space for less glamorous aspects of scientific work, such as repetitiveness, negative results, and lack of funding. The effect of this is that actual scientists working in these organisations can find it very difficult to connect the external glamorous story-telling with their own daily work experiences - and hence find it difficult to negotiate a stable and coherent identity for themselves [Felt and Fochler, 2012].

Another aspect of such organisational story-telling about science is the increasing celebrification of scientists [Fahy, 2015]. Most such heroic geniuses are white males and their creation often follows a classic narrative curve in which hard work in a competitive environment finally pays off for the main character of the story [Ganetz, 2016]. In addition, the focus on the unique individual supports a myth of excellent science as being de-coupled from any organisational ties, and as a result of pure genius - thereby also supporting an image of science as untouched by social relations, power hierarchies, or fights over resources.

The celebrification of scientists suggests a possible rise of a fan culture. So far that has not materialised to any large degree, although there has been newspaper speculation about a so-called 'Brian Cox effect', where more students apply to study physics and math due to Cox's media ubiquity [Vasagar, 2011]. Rather, when it comes to the general public it is arguably still the case that many citizens see it as a citizenly duty to take an interest in science and technology [Pew Research Center Science \& Society, 2015]. While there has been scholarly discussion of the idea of scientific citizenship [Elam and Bertilsson, 2003], here it suffices to say that engagement with science communication is not something publics do separately from the other things that matter to them in their lives. Rather, interest and engagement with science (or lack thereof) are shaped by the many identities individuals have, whether those stem from family roles, professional identities, political ideologies, or membership of social groups. However, public story-telling about science also offers resources for individual and collective sense-making about identities in a knowledge society. Emily Dawson [2014] and Mike Michael [1996] have both described how science communication activities can be designed in ways that make publics construct their own identity as separate and outside the domain of scientific citizenship. Viewing science communication as identity work therefore opens up a number of directions for research (and practice), helping us to enquire what public stories about science are doing to organisational identities, to public images of scientists, and to citizens' identities themselves. 


\subsection{Science communication as fiction}

Culture, we have suggested, is inextricably linked to storytelling. In this section we therefore highlight the prominence of fiction and narrative in a cultural approach to science communication. As evidence emerges that facts presented on their own do not have the persuasive power that was once assumed, science communicators have looked for more effective approaches to science communication that do not rely on science literacy [Bubela et al., 2009; Gregory and Lock, 2008; Nisbet and Scheufele, 2009]. The failure of persuasive approaches based on facts alone has led some science communication scholars to promote the use of fictional narratives and storytelling [Dahlstrom, 2014; Kaplan and Dahlstrom, 2017; Martinez-Conde and Macknik, 2017; Negrete and Lartigue, 2010]. Many high profile scientific organisations - most prominently the US National Academy of Sciences' Science and Entertainment Exchange and USC's Hollywood Health and Society - have developed programs that utilise fictional narratives for persuasive purposes [Kirby, 2017]. These organisations have gravitated to fictional narratives for science communication because stories can provide the public with a useful tool for making choices regarding scientific issues by setting out the context, establishing the stakes involved, providing useful information, and offering potential solutions. A cultural approach to science communication demands both awareness of these developments and reflexive engagement with the ways that science story-telling is becoming part of popular culture, and thus meaning-making at the societal scale.

Fictional narratives in science communication represent a dramatic shift away from approaches based on the unambiguous dissemination of facts. Fiction's ability to create its own version of the truth is what makes it attractive to scientists looking for alternative ways to persuade otherwise resistant audiences about issues related to science. Research on narrative persuasion demonstrates how fictional stories are effective in altering attitudes and behaviours [Moyer-Gusé and Dale, 2017].

Narratives have a powerful persuasive capacity because they reduce various forms of resistance to persuasion. Fiction fosters 'transportation' into a narrative world, which involves an integrative melding of attention, imagery, and feelings that become focused on story events [Green, Brock and Kaufman, 2004]. Transportation can have powerful persuasive consequences because it promotes emotional engagement with the characters in ways that can never be accomplished with the mere presentation of facts. Fiction's ability to generate emotional engagement is a major reason for the development of the genre of 'cli-fi' (climate fiction) in literature, film, and theatre over last decade [Johns-Putra, 2016; Svoboda, 2016]. Cli-fi is an effective form of climate communication because it can "translat[e] graphs and scientific jargon into experience and emotion" [Tuhus-Dubrow, 2013].

Fictional stories also convey aspects of science that have nothing to do with scientific facts or science literacy. Communicating science in fiction forces us to move beyond simplistic notions of science as merely a collection of facts in a textbook and to consider science as a larger cultural institution. To take one example, the 2016 film Arrival is about scientists working to communicate with aliens that have landed on earth. There are certainly scientific facts about linguistics and physics mentioned in the film. But the narrative communicated much more about science as a cultural institution, including the nature of scientific inquiry, the interactions between different scientific fields, scientific rivalries, international scientific collaborations, and scientists as people. The fictional story also depicted 
the different ways in which scientists interact with other cultural institutions including universities, the government, and the military.

This means that fictional narratives can communicate all the significant elements in the fact-producing process called science, including the political, economic, and social uses of science [Kirby, 2011]. Several studies show that it is the 'cultural meanings' of science, and not scientific knowledge, that may be the most significant element contributing to public attitudes toward science [Kirby, 2017; Nisbet and Scheufele, 2009]. Fictional stories can significantly influence public attitudes toward science by shaping, cultivating, or reinforcing these cultural meanings of science. Ultimately, the use of fiction for science communication is valuable because it contextualises science's implications for society, its value as a human activity, the consequences of its use or misuse, and its ideological status. Thinking about science communication in terms of fiction further gives insight into the central stories that (modern) societies tell about science, and therefore into how they make sense of science's nature, role, and potential.

\subsection{Science communication as emotional}

If culture is understood as meaning-making, it is closely intertwined not just with reason but with affect [Hemmings, 2005]. The way in which individuals and groups make sense of the world, in other words, is through emotional experiences as much as arguments and facts. Understanding meaning-making involves understanding the emotions that work to shape those meanings; in the context of science communication, there is therefore a need to be attentive to emotion as an integral part of what it is to produce or consume that communication. A cultural approach to science communication should involve analytical attention to the emotions that science triggers or that public communication seeks to promote, as well as the thoughtful use of emotion within science communication practice.

This is, in some ways, an obvious point. Recent years in particular have seen attention to the emotions connected to public presentations of science, and especially to public responses that may appear too emotional [Cook, 2004; Penders, 2017], while there is a long history of the promotion of the 'correct' emotions for engagement with science - curiosity, wonder, and awe, for instance [Daston and Park, 2001; Harrison, 2001]. At the same time scholarship of science communication has tended to focus either on learning or on public attitudes, only recently turning to the role of embodiment, aesthetics, and affect in shaping experiences of public communication [Davies, 2014; Harvey, 2009; Michael, Wilkie and Ovalle, 2018]. There is therefore a continuing need to acknowledge, and explore, emotion within science communication.

It is important to note that there is a long tradition of research that has looked at the role of emotions in science [see Barbalet, 2002, for one review]. As a starting point this emphasises - and it is now widely accepted - that scientific practice is intrinsically emotional, and that distinctions between emotion and reason are overly simplistic [White, 2009]. Scientists are, generally speaking, happy to describe their work in terms of emotions of passion, creativity, or curiosity [Barbalet, 2002; Koppman, Cain and Leahey, 2015] — at least in private spaces, if not always in public [Gilbert and Mulkay, 1984]. These emotions also frequently 
occur in discussions of what science communication should do to its audiences. Producers of science communication, whether they are scientists or science communicators, may describe participation in communication as personally pleasurable, as well talking about wanting to trigger emotions such as interest, curiosity, enthusiasm or appreciation in their audiences [Poliakoff and Webb, 2007; Martín-Sempere, Garzón-García and Rey-Rocha, 2008]. 'Fun', as Erik Stengler [2017] has commented, is particularly ubiquitous (and has led to discussions of whether this should necessarily be the case).

We also have some knowledge of what those who use science communication get out of it in terms of emotions, whether those are positive or negative. Successful science communication - if we understand this as an experience that triggers positive emotions - may be experienced as entertaining, informative, interesting, new or surprising, or as inducing curiosity [Bultitude and Sardo, 2012;

Fogg-Rogers et al., 2015; Jensen and Buckley, 2014]. Learning, and the pleasures of (self) education, seem particularly key. Less positively, users may report confusion, boredom, or frustration [Davies, 2019]. Indeed, some individuals may experience emotions of exclusion or isolation: recent work has shown that science communication continues to be implicitly designed with specific audience groups (generally those who are already well-served) in mind, leaving others with the sense that it is something that is 'not for us' [Burns and Medvecky, 2016; Dawson, 2014].

It is important to note that exploration of the emotions that are intended or sought within science communication, on the one hand, and actually experienced, on the other, is at an early stage, and that there are many questions remaining. In particular it seems important to look at what we might call the emotional landscape of an instance of science communication as a whole, and especially the ways in which there may be a mismatch between desired, and actually experienced, emotions. Such analysis can help us to ask: what is any piece of communication asking of its audiences, and what do its audiences actually want from it? Beyond this, however, such explorations can lead us to the meanings that science communication has within particular groups or societies. A desire to trigger enthusiasm suggests a specific relation that publics should have to science; a fear of boredom points both to the way in which this emotion is understood today - as something to be avoided at all costs - and to the idea that science communication should be seductively entertaining. Studying emotions therefore allows us to drill down into the commonsense assumptions, values, and knowledge of cultures, and to explore the kinds of stories that are told about science within them.

\section{Conclusion}

In closing we want to briefly reflect on what these four different but interconnected approaches to 'culture' can offer to the study and practice of science communication. Perhaps most importantly, they show us how we might move past endless debates about 'deficit vs. dialogue' or recurring attempts to define 'models' of science communication [see discussion in Davies and Horst, 2016]. Recent attempts to catalogue encounters with science, for example, have struggled with the distinctions between 'science communication', 'public engagement in science', and 'informal science education' [National Research Council, 2009; Crowley, 2018; McCallie et al., 2009; Storksdieck et al., 2018]. Focusing on meaning-making also moves us from a sole focus on producers' intentions to highlight the experiences of 
all of the individuals or groups who are involved in science communication. We begin to see the cultural matrix in which science necessarily functions, without missing the other elements of culture that are equally part of the matrix.

At a practical level, focusing on culture and meaning-making opens up new ways of analysing empirical material. These foci move away from the existing categories of dissemination and dialogue, which focus on directionality of information, and instead move towards the quality and meaning of communication. For example, as efforts to link science and art grow worldwide, attempts to imbue art with information-transfer goals have struggled with the insistence of art and artists that art exists for its own sake, and that its function in society is to foster emotion and experience. This insistence does not map onto the well-trodden territory in which the form of communication must be categorised as deficit or dissemination. Science communication as culture or meaning-making forces us to look at the qualities of communication, allowing us to consider it within the varied contexts in which it is experienced. Reconsidering science communication as meaning-making thus opens up new ways of understanding and valuing the unique attributes of cases like art-science collaboration, or the use of science in fiction, or long-term experiences of advertising that draws on scientific tropes.

Ultimately, thinking of public science stories as culture and meaning can, we argue, offer a fresh perspective that values public communication in its many and diverse forms, from public lectures to public consultations. Debates about science literacy or information transfer have occupied the field for at least two generations, and often feel repetitive or ineffectual. Instead, adopting the cultural approach we have argued for as a frame not just for a particular study, but as a platform for viewing the entire field, offers the potential for seeing further across the landscape of intellectual inquiry and cultural production. Considering experience, identity, fiction, and emotion can link public communication of science and technology to concerns across the human experience - concerns of care, equality, respect, and trust. Looking outward leads us to richer understanding of our own domain.

\section{References}

Baram-Tsabari, A. and Lewenstein, B. V. (2017). 'Science communication training: what are we trying to teach?' International Journal of Science Education, Part B 7 (3), pp. 285-300. https://doi.org/10.1080/21548455.2017.1303756.

Barbalet, J. (2002). 'Science and emotions'. The Sociological Review 50 (S2), pp. 132-150.https://doi.org/10.1111/j.1467-954x.2002.tb03595.x.

Bauer, M. W. and Gregory, J. (2007). 'PUS Inc.: from journalism to corporate communication in post-War Britain'. In: Journalism, Science and Society: between News and Public Relations. Ed. by M. W. Bauer and M. Bucchi. London, U.K.: Routledge, pp. 33-52. https://doi.org/10.4324/9780203942314.

Blue, G. (2018). 'Science communication is culture: foregrounding ritual in the public communication of science'. Science Communication 41 (2), pp. 243-253. https://doi.org/10.1177/1075547018816456.

Bray, B., France, B. and Gilbert, J. K. (2012). 'Identifying the Essential Elements of Effective Science Communication: What do the experts say?' International Journal of Science Education, Part B 2 (1), pp. 23-41. https://doi.org/10.1080/21548455.2011.611627. 
Broks, P. (2017). 'Science communication: process, power and politics'. JCOM 16 (04), C02. URL: https://jcom.sissa.it/archive/16/04/JCOM_1604_2017_C01 /JCOM_1604_2017_C02.

Brossard, D. and Lewenstein, B. V. (2010). 'A Critical Appraisal of Models of Public Understanding of Science: Using Practice to Inform Theory'. In: Communicating Science; New Agendas in Communication. Ed. by L. Kahlor and P. A. Stout. New York, U.S.A.: Routledge, Taylor \& Francis, pp. 11-39.

Bubela, T., Nisbet, M. C., Borchelt, R., Brunger, F., Critchley, C., Einsiedel, E., Geller, G., Gupta, A., Hampel, J., Hyde-Lay, R., Jandciu, E. W., Jones, S. A., Kolopack, P., Lane, S., Lougheed, T., Nerlich, B., Ogbogu, U., O’Riordan, K., Ouellette, C., Spear, M., Strauss, S., Thavaratnam, T., Willemse, L. and Caulfield, T. (2009). 'Science communication reconsidered'. Nature Biotechnology 27 (6), pp. 514-518. https://doi .org/10.1038/nbt0609-514.

Bucchi, M. (2008). 'Of deficits, deviations and dialogues: theories of public communication of science'. In: Handbook of Public Communication of Science and Technology. Ed. by M. Bucchi and B. Trench. London, U.K. and New York, U.S.A.: Routledge, pp. 57-76.

- (2013). 'Style in science communication'. Public Understanding of Science 22 (8), pp. 904-915. https://doi .org/10.1177/0963662513498202.

Bucchi, M. and Trench, B., eds. (2014). Routledge Handbook of Public Communication of Science and Technology. 2nd ed. London, U.K. and New York, U.S.A.: Routledge. https://doi .org/10.4324/9780203483794.

Bultitude, K. and Sardo, A. M. (2012). 'Leisure and Pleasure: Science events in unusual locations'. International Journal of Science Education 34 (18), pp. 2775-2795. https://doi.org/10.1080/09500693.2012.664293.

Burns, M. and Medvecky, F. (2016). 'The disengaged in science communication: how not to count audiences and publics'. Public Understanding of Science 27 (2), pp. 118-130. https://doi .org/10.1177/0963662516678351.

Carey, J. (1989). Communication as culture: essays on media and society. London, U.K.: Unwin Hyman.

Cook, G. (2004). Genetically modified language. London, U.K. and New York, NY, U.S.A.: Routledge.

Crowley, K. (2018). Are the fields of informal science education and science communication adjacent or connected? A bibliometric study of research journals from 2012 to 2016. Washington, DC, U.S.A.: CAISE (Center for Advancement of Informal Science Education).

Czarniawska, B. (1997). Narrating the organization - dramas of institutional identity. Chicago, IL, U.S.A.: The University of Chicago Press.

Dahlstrom, M. F. (2014). 'Using narratives and storytelling to communicate science with nonexpert audiences'. Proceedings of the National Academy of Sciences 111 (Supplement 4), pp. 13614-13620. https://doi.org/10.1073/pnas.1320645111.

Daston, L. and Park, K. (2001). Wonders and the order of nature, 1150-1750. Zone Books.

Davies, S. R. (2014). 'Knowing and loving: public engagement beyond discourse'. Science \& Technology Studies 27 (3), pp. 90-110. 
Davies, S. R. (2019). 'Science communication as emotion work: negotiating curiosity and wonder at a science festival'. Science as Culture, pp. 1-24. https://doi.org/10.1080/09505431.2019.1597035.

Davies, S. R. and Horst, M. (2016). Science Communication: culture, identity and citizenship. London, New York and Shanghai: Palgrave Macmillan. https://doi.org/10.1057/978-1-137-50366-4.

Dawson, E. (2014). “Not designed for us": How science museums and science centers socially exclude low-income, minority ethnic groups'. Science Education 98, pp. 981-1008.

Dewey, J. (1934). Art as experience. New York, NY, U.S.A.: Perigree Press.

- (1938). Experience and education. New York, NY, U.S.A.: Free Press.

DiMaggio, P. J. and Powell, W. W. (1983). 'The iron cage revisited: institutional isomorphism and collective rationality in organizational fields'. American Sociological Review 48 (2), p. 147. https : //doi .org/10.2307/2095101.

du Gay, P., Hall, S., Janes, L., Mackay, H. and Negus, K. (1997). Doing cultural studies: the story of the Sony Walkman. SAGE Publications.

Durant, J. R., Evans, G. A. and Thomas, G. P. (1989). 'The public understanding of science'. Nature 340 (6228), pp. 11-14. https: //doi . org/10.1038/340011a0.

Elam, M. and Bertilsson, M. (2003). 'Consuming, engaging and confronting science'. European Journal of Social Theory 6 (2), pp. 233-251. https://doi.org/10.1177/1368431003006002005.

Fahy, D. (2015). The new celebrity scientists. Rowman \& Littlefield Publishers.

Fahy, D. and Caulfield, T. (2016). 'Science, celebrities and public engagement'. Issues in Science \& Technology 32 (4), pp. 24-26.

Fahy, D. and Lewenstein, B. V. (2014). 'Scientists in popular culture'. In: Handbook of public communication of science and technology. Ed. by M. Bucchi and B. Trench. 2nd ed. London, U.K.: Routledge, pp. 83-96.

Felt, U. and Fochler, M. (2012). 'Re-ordering Epistemic Living Spaces: On the Tacit Governance Effects of the Public Communication of Science'. In: The Sciences' Media Connection - Public Communication and its Repercussions. Ed. by S. Rödder, M. Franzen and P. Weingart. Vol. 28. Dordrecht, Netherlands: Springer, pp. 133-154.

Felt, U. and Wynne, B. (2007). Science and governance: taking european knowledge society seriously. URL: http://ec. europa.eu/research/science-society/docum ent_library/pdf_06/european-knowledge-society_en.pdf.

Fogg-Rogers, L., Bay, J. L., Burgess, H. and Purdy, S. C. (2015). "“Knowledge is power": a mixed-methods study exploring adult audience preferences for engagement and learning formats over 3 years of a health science festival'. Science Communication 37 (4), pp. 419-451. https://doi.org/10.1177/1075547015585006.

Ganetz, H. (2016). 'The Nobel celebrity-scientist: genius and personality'. Celebrity Studies 7 (2), pp. 234-248. https: //doi.org/10.1080/19392397.2015.1088394.

Geertz, C. (1973). 'Thick description: toward an interpretive theory of culture'. In: The interpretation of cultures: selected essays. Basic Books, pp. 3-30.

Gilbert, N. and Mulkay, M. (1984). Opening Pandora's box: a sociological analysis of scientists' discourse. Cambridge, U.K.: Cambridge University Press. 
Green, M. C., Brock, T. C. and Kaufman, G. F. (2004). ‘Understanding media enjoyment: the role of transportation into narrative worlds'. Communication Theory 14 (4), pp. 311-327. https://doi.org/10.1111/j.1468-2885.2004.tb00317.x.

Gregory, J. and Lock, S. J. (2008). 'The Evolution of 'Public Understanding of Science': Public Engagement as a Tool of Science Policy in the UK'. Sociology Compass 2 (4), pp. 1252-1265. https://doi.org/10.1111/j.1751-9020.2008.00137.x.

Hall, S. (1997). Representation: cultural representations and signifying practices. London, U.K.: Sage.

Halpern, M. K. (2012). 'Across the great divide: boundaries and boundary objects in art and science'. Public Understanding of Science 21 (8), pp. 922-937. https://doi.org/10.1177/0963662510394040.

Harrison, P. (2001). 'Curiosity, forbidden knowledge and the reformation of natural philosophy in early modern England'. Isis 92 (2), pp. 265-290. https://doi.org/10.1086/385182.

Harvey, M. (2009). 'Drama, talk and emotion: omitted aspects of public participation'. Science, Technology, \& Human Values 34 (2), pp. 139-161. https://doi.org/10.1177/0162243907309632.

Hatch, M. J. and Schultz, M. (1997). 'Relations between organizational culture, identity and image'. European Journal of Marketing 31 (5/6), pp. 356-365. https://doi.org/10.1108/eb060636.

Hemmings, C. (2005). 'INVOKING AFFECT: cultural theory and the ontological turn'. Cultural Studies 19 (5), pp. 548-567. https://doi.org/10.1080/09502380500365473.

Horst, M. (2013). 'A Field of Expertise, the Organization, or Science Itself? Scientists' Perception of Representing Research in Public Communication'. Science Communication 35 (6), pp. 758-779. https://doi.org/10.1177/1075547013487513.

Horst, M. and Michael, M. (2011). 'On the shoulders of idiots: re-thinking science communication as 'event". Science as Culture 20 (3), pp. 283-306. https://doi.org/10.1080/09505431.2010.524199.

Illingworth, S. and Allen, G. (2016). Effective science communication. A practical guide to surviving as a scientist. Bristol, U.K. and Philadelphia, PA, U.S.A.: IOP Publishing. https://doi.org/10.1088/978-0-7503-1170-0.

Jasanoff, S. (2017). 'Science and democracy'. In: The handbook of science and technology studies. Ed. by U. Felt, R. Fouché, C. Miller and L. Smith-Doerr. Boston, MA, U.S.A.: MIT Press, pp. 259-287.

Jasanoff, S. and Kim, S.-H. (2015). Dreamscapes of Modernity: Sociotechnical Imaginaries and the Fabrication of Power. Chicago, U.S.A.: The University of Chicago Press.

Jensen, E. and Buckley, N. (2014). 'Why people attend science festivals: interests, motivations and self-reported benefits of public engagement with research'. Public Understanding of Science 23 (5), pp. 557-573.

Johns-Putra, A. (2016). 'Climate change in literature and literary studies: from cli-fi, climate change theater and ecopoetry to ecocriticism and climate change criticism'. Wiley Interdisciplinary Reviews: Climate Change 7 (2), pp. 266-282. https://doi.org/10.1002/wcc. 385. 
Kaiser, D., Durant, J., Levenson, T., Wiehe, B. and Linett, P. (2014). Report of findings: September 2013 workshop.

Kaplan, M. and Dahlstrom, M. F. (2017). 'How narrative functions in entertainment to communicate science'. In: Oxford handbook on the science of science communication. Ed. by K. H. Jamieson, D. Kahan and D. A. Scheufele. Oxford, U.K.: Oxford University Press, pp. 311-319.

Kirby, D. A. (2011). Lab Coats in Hollywood. Cambridge MA, U.S.A.: MIT Press. URL: https://mitpress .mit. edu/books/lab-coats-hollywood.

- (2017). 'The changing popular images of science'. In: Oxford handbook on the science of science communication. Ed. by K. H. Jamieson, D. Kahan and D. A. Scheufele. Oxford, U.K.: Oxford University Press, pp. 291-300.

Koppman, S., Cain, C. L. and Leahey, E. (2015). 'The joy of science: disciplinary diversity in emotional accounts'. Science, Technology, E Human Values 40 (1), pp. 30-70. https://doi.org/10.1177/0162243914537527.

Kunda, G. (2006). Engineering culture: control and commitment in a high-tech corporation. Temple University Press.

Linett, P. (2013). 'Interview: Ben Lillie on science and the storytelling revival'. Curator: The Museum Journal 56 (1), pp. 15-19. https://doi.org/10.1111/cura.12003.

Longnecker, N. (2016). 'An integrated model of science communication - More than providing evidence'. JCOM 15 (05), Y01. URL: https://jcom.sissa.it/archive/15/05/JC0M_1505_2016_Y01.

Martín-Sempere, M. J., Garzón-García, B. and Rey-Rocha, J. (2008). 'Scientists' motivation to communicate science and technology to the public: surveying participants at the Madrid Science Fair'. Public Understanding of Science 17 (3), pp. 349-367. https://doi.org/10.1177/0963662506067660.

Martinez-Conde, S. and Macknik, S. L. (2017). 'Opinion: finding the plot in science storytelling in hopes of enhancing science communication'. Proceedings of the National Academy of Sciences 114 (31), pp. 8127-8129. https://doi.org/10.1073/pnas.1711790114.

McCallie, E., Bell, L., Lohwater, T., Falk, J. H., Lehr, J. L., Lewenstein, B. V. and Needham, C. (2009). Many Experts, Many Audiences: Public Engagement with Science and Informal Science Education. Washington, D.C., U.S.A.: Center for Advancement of Informal Science Education (CAISE).

URL: http://digitalcommons.calpoly.edu/eth_fac/12/.

Michael, M. (1996). 'Ignoring science: discourses of ignorance in the public understanding of science'. In: Misunderstanding science? Ed. by A. Irwin and B. Wynne. Cambridge, U.K.: The Press Syndicate of the University of Cambridge, pp. 107-125.

- (2002). 'Comprehension, apprehension, prehension: heterogeneity and the public understanding of science'. Science, Technology, E Human Values 27 (3), pp. 357-378. https://doi.org/10.1177/016224390202700302.

Michael, M., Wilkie, A. and Ovalle, L. (2018). 'Aesthetics and affect: engaging energy communities'. Science as Culture 27 (4), pp. 439-463. https://doi.org/10.1080/09505431.2018.1490709.

Moyer-Gusé, E. and Dale, K. (2017). 'Narrative persuasion theories'. In: The International Encyclopedia of Media Effects. Ed. by P. Rössler. Chichester, U.K.: Wiley-Blackwell. https://doi.org/10.1002/9781118783764.wbieme0082. 
National Research Council (2009). Learning Science in Informal Environments: People, Places, and Pursuits. Ed. by P. Bell, B. Lewenstein, A. W. Shouse and M. A. Feder. Washington, D.C., U.S.A.: National Academies Press. URL: http://www . nap. edu/catalog/12190.

Negrete, A. and Lartigue, C. (2010). 'The science of telling stories: Evaluating science communication via narratives (RIRC method)'. Journal of Media and Communication Studies 2 (4), pp. 98-110. URL: http: //www . academicjournals . o rg/article/article1380097133_Negrete\%20and\%20Lartigue.pdf.

Nisbet, M. C. and Scheufele, D. A. (2009). 'What's next for science communication? Promising directions and lingering distractions'. American Journal of Botany 96 (10), pp. 1767-1778. https://doi.org/10.3732/ajb. 0900041.

Penders, B. (2017). 'Marching for the myth of science: a self-destructive celebration of scientific exceptionalism'. EMBO reports 18 (9), pp. 1486-1489. https://doi.org/10.15252/embr. 201744935.

Pew Research Center Science \& Society (11th December 2015). Americans' interest in science, health and other topics. [Blog post].

URL: http://www . pewresearch.org/science/(2015)/12/11/public-interest -in-science-health-and-other-topics/.

Poliakoff, E. and Webb, T. L. (2007). 'What factors predict scientists' Intentions to participate in public engagement of science activities?' Science Communication 29 (2), pp. 242-263.

Sarbin, T. R. (1986). 'The narrative as a root metaphor for psychology'. In: Narrative psychology: the storied nature of human conduct. Westport, CT, U.S.A.: Praeger Publishers/Greenwood Publishing Group, pp. 3-21.

Sardo, A. M. and Grand, A. (2016). 'Science in culture: audiences' perspective on engaging with science at a summer festival'. Science Communication 38 (2), pp. 251-260. https://doi.org/10.1177/1075547016632537.

Silva, J. and Bultitude, K. (2009). 'Best practice in communications training for public engagement with science, technology, engineering and mathematics'. JCOM 08 (02), A03.

URL: https://jcom.sissa.it/archive/08/02/Jcom0802\%282009\%29A03.

Stengler, E. (2017). 'Science communicators need to get it: science isn't fun'. In: The museums blog book. Ed. by G. Farnell. MuseumsEtc, pp. 496-501.

Storksdieck, M., Bevan, B., Risien, J., Nilson, R. and Wills, K. (2018). Charting the intersection of informal STEM education and science communication: results of a social network study. Washington, DC, U.S.A.: CAISE (Center for Advancement of Informal Science Education).

Svoboda, M. (2016). 'Cli-fi on the screen(s): patterns in the representations of climate change in fictional films'. Wiley Interdisciplinary Reviews: Climate Change 7 (1), pp. 43-64. https://doi.org/10.1002/wcc. 381.

Taylor, J. R. and van Every, E. J. (2008). The emergent organization: communication as its site and surface. Hove, U.K.: Psychology Press.

Trench, B. (2008). 'Towards an analytical framework of science communication models'. In: Communicating science in social contexts. Dordrecht, The Netherlands: Springer, pp. 119-135. https://doi.org/10.1007/978-1-4020-8598-7_7.

Tuhus-Dubrow, R. (2013). 'Cli-fi: birth of a genre'. Dissent 60 (3), pp. 58-61. https://doi.org/10.1353/dss.2013.0069. 
Vasagar, J. (18th August 2011). 'A-levels boom in maths and science credited to 'Brian Cox effect'. The Guardian. URL: https: //www . theguardian. com/educati on/2011/aug/18/a-levels-boom-maths-science.

Weick, K. E. (2000). Making sense of the organization. Wiley.

White, P. (2009). 'Introduction: the emotional economy of science'. Isis 100 (4), pp. 792-797. https://doi.org/10.1086/652019.

Authors

Sarah R. Davies is the co-author of 'Science Communication: Culture, Identity and Citizenship' (Palgrave, 2016) and is based at the Norwegian University of Science and Technology. E-mail: sarah.r.davies@ntnu.no.

Megan Halpern works at the intersection of art and science, and is at Michigan State University. E-mail: mhalpern@msu.edu.

Maja Horst is Professor and Head of Department at the University of Copenhagen. E-mail: horst@hum.ku.dk.

David A. Kirby is Professor of Science Communication Studies at the University of Manchester. E-mail: david.kirby@manchester.ac.uk.

Bruce Lewenstein is Professor of Science Communication at Cornell. E-mail: b.lewenstein@cornell.edu.

How to cite

Davies, S. R., Halpern, M., Horst, M., Kirby, D. A. and Lewenstein, B. (2019). 'Science stories as culture: experience, identity, narrative and emotion in public communication of science'. JCOM 18 (05), A01. https://doi.org/10.22323/2.18050201. 